\title{
Recipient and Instructor perspectives of an adapted exercise-based fall prevention program for older adults with vision impairment: a qualitative study nested within a randomised controlled trial
}

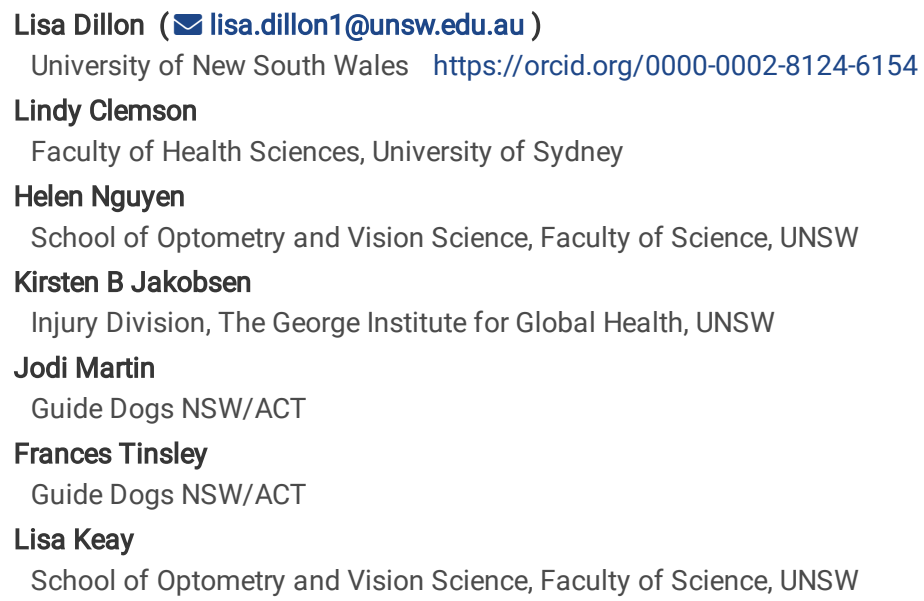

Research article

Keywords: Vision, low; accidental falls; exercise; habits; program development

Posted Date: September 2nd, 2019

DOI: https://doi.org/10.21203/rs.2.13880/v1

License: (c) (1) This work is licensed under a Creative Commons Attribution 4.0 International License. Read Full License 


\section{Abstract}

Background People with vision impairment are at an increased risk of falls compared with their sighted peers, but have very little access to existing community fall prevention programs. The Lifestyle-integrated Functional Exercise (LiFE) program can prevent falls in older people and may be suitable for adults aged $\geq 50$ with vision impairment. Methods The LiFE program was adapted for older adults with vision impairment ( $\mathrm{v}$-LiFE) and delivered by Orientation and Mobility Specialists (Instructors), who are experienced with individualised programs for people with vision impairment. Perspectives of older adults with vision impairment (recipients) receiving the v-LiFE program and their Instructors were explored through semi-structured interviews. Results Of 73 trained Instructors, 51(70\%) delivered at least one session to a total of 240 older adults with vision impairment between March 2017 and May 2019 . Of these, $11 / 51(22 \%)$ Instructors and 154/172(90\%) of invited recipients (until thematic saturation was reached) were interviewed. Six key themes were identified relating to recipient (delivery aptitude; social norms; habit formation) and Instructor (individualised adaptation; complimentary to scope of practice; challenges to delivery) perspectives. Instructors considered delivering v-LiFE as an extension of their scope of work. Conclusions Older adults with vision impairment demonstrated positive attitudes towards the program, but younger or more physically fit recipients considered the program too easy for them. The perspectives of recipients and instructors indicate that the v-LiFE program delivered within existing services may fill the gap for a fall prevention program for people with vision impairment.

\section{Background}

In Australia, the population of people aged $\geq 65$ years is projected to increase from $14 \%$ in 2012 to $18.3-19.4 \%$ in $2031 .{ }^{1}$ Over $80 \%$ of injury-related hospital admissions of people $\geq 65$ years are a result of falls, representing the leading cause of injury-related morbidity and mortality in older Australians. ${ }^{2}$ Older adults with vision impairment experience deteriorated postural stability at a younger age $(<60 \text { years })^{3}$ and have higher risk of falls and fall-related injuries, compared with their sighted peers. ${ }^{4,5}$ A recent systematic review showed that exercise alone can reduce falls by up to $39 \%$ in high-risk populations for programs which include $3+$ hours of exercise per week and focus on balance. ${ }^{6}$ To date, however, there are no proven exercise-based falls prevention programs for older adults with vision impairment. ${ }^{7}$

The Lifestyle-integrated Functional Exercise (LiFE) program has been shown to decrease falls by $31 \%$ in community-dwelling older adults. ${ }^{8}$ The LiFE program requires participants to integrate strength and balance activities into their everyday routines, to enhance adoption and adherence of the program through habit formation. ${ }^{8,9}$ Following pilot testing in adults $\geq 50$ years with vision impairment ${ }^{10}$, an adapted program for this population ( $v$-LiFE) was proposed for state-wide evaluation throughout New South Wales (NSW) and the Australian Capital Territory (ACT), Australia. The program was delivered by Orientation and Mobility Specialists (Instructors) from a community organisation (Guide Dogs NSW/ACT) ${ }^{11}$, with experience delivering individualised programs that enhance safe, confident and independent travel of people with vision impairment in their home or community environment. ${ }^{12}$

Little is known about the perspectives of Instructors delivering falls prevention programs to their clients, as these programs are usually outside Instructors' scope of practice. ${ }^{13}$ Similar professions (e.g. occupational therapy) routinely investigate professionals' perspectives to inform clinical practice as part of their evidence-based models. ${ }^{14}$ Positive findings in the general community, not replicated in those with vision impairment, warrant further investigation of how programs can be adapted to improve accessibility and adherence of people with vision impairment. This study documents the adaptation and implementation of the v-LiFE program from the perspectives of Instructors involved in delivery, as well as the older adults with vision impairment receiving the program.

\section{Methods}

Instructor and recipient perspectives were triangulated to systematically investigate delivery of an exercise-based falls prevention program in people with vision impairment (v-LiFE). This aim was addressed through a range of data sources:

1. Documenting initial adaptations of LiFE for older adults with vision impairment (v-LiFE), as well as adaptations reported by Instructors through interview;

2. Documenting the level of training and support required by Instructors to deliver this program, including initial training and ongoing support (email, phone, in person and expert or peer);

3. Semi-structured interviews with recipients following completion of the v-LiFE program to investigate program acceptability;

4. Semi-structured interviews with Instructors to investigate acceptability of program delivery.

The behaviour change wheel (Figure 1) intervention functions (middle wheel) and COM-B model (inner wheel), were used as the framework to implement and evaluate program delivery. The behaviour change wheel was chosen because of its emphasis on how specific intervention elements can affect individual behaviour change. ${ }^{15}$ Specific intervention functions related to this investigation included enablement, environmental restructuring, education, persuasion, incentivisation and coercion. ${ }^{15}$

\section{Participants}

\section{Older adults with vision impairment}

Older adults with vision impairment were recruited from the intervention group of a randomised controlled trial (RCT). ${ }^{11}$ Eligibility included communitydwelling adults $\geq 50$ years with vision impairment severe enough to interfere with daily living, and no diagnosis of dementia. A total of 294 participants were allocated to receive the v-LiFE program, of which 172 had finished the program at the time of interviews for the present study.

Page 2/10 
Instructors from Guide Dogs NSW/ACT, trained in the v-LiFE program, who delivered at least one v-LiFE program session to an older adult with vision impairment were eligible to participate in the present study. A random sample of Instructors were invited for interview, which were conducted until data saturation was reached.

\section{Program}

The original LiFE program was designed using habit formation theory ${ }^{8,9}$, and aligns with the ethos of the behaviour change wheel. ${ }^{15}$ The philosophy of LiFE is embedding strength and balance activities into everyday life. For example, a recipient may challenge their strength by bending their knees as they stack the dishwasher, or challenge their balance by standing with their feet in tandem while washing dishes. As mastery of an activity occurs, recipients are encouraged to upgrade activities to continue challenging their strength and balance. The program uses specially designed self-monitoring tools (activity planner and activity counter) to reinforce activity completion. Recipients are given a participant manual, which includes descriptions of the strength and balance activities and examples of opportunities to practice. The manual also includes case studies of past recipients to increase engagement through identification with the program as something in which a peer would participate. LiFE is delivered over five weekly sessions, followed by two booster sessions and two phone calls, over a period of approximately three to five months.

\section{Training the Orientation and Mobility Specialists (Instructors)}

Instructors were trained in the v-LiFE program in a two-day workshop, by the designer of LiFE (LC) and a physiotherapist involved in program development. Instructors were provided ongoing support by the physiotherapist and an experienced colleague (LD). Email or phone support was recorded, as well as any time the physiotherapist or experienced colleague attended a session with Instructors.

\section{Older adults with vision impairment perspectives}

After completion of the v-LiFE program, recipients were invited to complete a post-intervention semi-structured telephone interview with an independent researcher $(\mathrm{HN})$. Although the v-LiFE program typically took three months, recipients were contacted four months' post-baseline to allow for any breaks within programs that may have occurred, or for those who may have required additional sessions. Interviews took approximately 15 minutes.

Yardley et al ${ }^{16}$ argues that individual attitudes towards exercise-based falls prevention programs can influence actual performance of program components. Recipients' attitudes to v-LiFE were measured using an open-ended version of the Attitudes to Falls-Related Intervention Scale (AFRIS), which is based on the widely-accepted Theory of Planned Behaviour. ${ }^{16}$ Open-ended AFRIS questions included: 'Describe how you found doing the v-LiFE program? Easy/hard? Enjoyable?' and 'Did you think the v-LiFE program was good for you? How?' (Additional file 1).

\section{Orientation and Mobility Specialist (Instructor) perspectives}

Instructor perspectives were investigated through semi-structured interviews. Interviews explored facilitators and challenges to program delivery, as well as suggestions for further adaptation of v-LiFE. Examples of questions included: 'What were the main challenges you experienced when delivering the program?' and 'What about v-LiFE could be adapted to help [Instructors] deliver the program?' (Additional file 2). Of particular interest was enablement ${ }^{15}$, since previous studies called into question the adherence of older adults with vision impairment to exercise-based falls prevention programs. ${ }^{17}$ Questions were asked about reducing barriers and increasing delivery of the v-LiFE program to older adults with vision impairment.

\section{Data analysis}

Transcripts of the semi-structured interviews from recipients and Instructors were analysed using QSR International NVivo 11 qualitative data analysis software. Using deductive analysis ${ }^{18}$, transcripts were coded by a researcher (LD) within the intervention functions and sources of behaviour from the behaviour change wheel, and checked for accuracy and clarity by a second researcher (LK). Illustrative quotes from recipients are included with their sex ( $M$ or F) and age, and from Instructors with their sex ( $\mathrm{M}$ or F), years of experience and number of recipients they delivered v-LiFE to. This study is reported in line with the CONSORT statement for nonpharmacologic treatments. ${ }^{19}$

\section{Results}

\section{Adaptation of LiFE for older people with vision impairment (v-LiFE)}

\section{Initial adaptations}

The participant manual, activity planner and activity counter all needed to be made accessible to people with vision impairment. ${ }^{11}$ The participant manual was modified into large print, electronic (PDF) and audio (CD) versions to suit a variety of vision conditions and preferences. The LiFE manual was also updated to shorten text, and case studies were replaced with examples of people with vision impairment, to ensure participants could identify with the program. The activity planner and activity counter were modified into large print, extra-large print, and electronic (PDF) versions. Participants were encouraged to use whatever device or method of recording they were already familiar with in order to increase compliance. Examples of recording methods included tally counters, voice recorders, counters in a box, marking calendars or electronically recording activities using spreadsheets or word processing software. 
Previous pilot testing ${ }^{10}$ revealed that the standard number of sessions for LiFE was insufficient to adequately train participants in all program activities. Consequently, Instructors were given the option to include an additional two sessions, if required. Instructors were encouraged to facilitate participants' learning by using tactile modelling, verbal instructions, and introduce cues to prompt action (behavioural, situational and environmental) and encourage practice, repetition and reinforcement of activities.

\section{Ongoing adaptations}

In the interviews, Instructors reported using a person-centred approach to adapting and delivering the program. Overall, the program was tailored to participants' preferences, home environment and health status. Table 1 shows specific adaptations reported by Instructors.

Table 1. Adaptations to the v-LiFE program as reported by Orientation and Mobility Specialists (Instructors)

\begin{tabular}{ll}
\hline Adaptations & Specific adaptations \\
\hline Physical & $\begin{array}{l}\text { Adapted program activities for comorbidities and injuries using performance in the v-LiFE Assessment Tool, } \\
\text { professional judgement and advice from the physiotherapist LiFE trainer }\end{array}$ \\
\hline $\begin{array}{l}\text { Program } \\
\text { materials }\end{array}$ & $\begin{array}{l}\text { Participant manual: Large text, audio, pdf } \\
\text { Recording devices: Large text activity planner and activity counter, word processing software document, } \\
\text { spreadsheets, voice recorder, beads } \\
\text { v-LiFE Assessment Tool: Used at the start to guide level of activities, but also used at the end to reinforce } \\
\text { progress }\end{array}$ \\
\hline $\begin{array}{l}\text { Activity } \\
\text { frequency }\end{array}$ & $\begin{array}{l}\text { Routine-based (as per LiFE) or allowed LiFE activities to be completed as a block based on participant } \\
\text { preference }\end{array}$ \\
\hline $\begin{array}{l}\text { Number of } \\
\text { sessions }\end{array}$ & $\begin{array}{l}\text { Additional sessions for older participants, those with health issues, or those having trouble remembering } \\
\text { activities }\end{array}$ \\
\hline $\begin{array}{l}\text { Prompts to } \\
\text { perform activities }\end{array}$ & $\begin{array}{l}\text { Prome item prompts (such as a tissue box out of place, or a tooth brush placed in a lower drawer) } \\
\text { Prompts specific to those with low vision: Coloured/big markers/stickers }\end{array}$ \\
\hline Family & Family assisted in recording and monitoring completion of activities \\
\hline
\end{tabular}

\section{Training and support required for Orientation and Mobility Specialists (Instructors) to deliver v-LiFE}

Seventy-three Instructors received two days of training (approximately 9 hours) in the v-LiFE program. Of these, 51 (69.9\%) delivered at least one session to participants between March 2017 and April 2019 (Table 2). Of these 51 Instructors, the physiotherapist provided phone or email support to seven (13.7\%) and two (3.9\%) Instructors, respectively. On Instructor request, the experienced colleague attended sessions with two (3.9\%) Instructors, and provided phone or email support to $14(27.5 \%)$ and $12(23.5 \%)$ Instructors, respectively.

Table 2. Support provided to Orientation and Mobility Specialists (Instructors) by the physiotherapist and experienced colleague

\begin{tabular}{lr}
\hline \multicolumn{2}{c}{ Trained Instructors (N = 73) } \\
\hline $\begin{array}{l}\text { Instructors delivered v-LiFE: n (\%) } \\
\text { Physiotherapist support }\end{array}$ & $51(69.9)$ \\
& \\
Observed session: n (\%) & $0(0)$ \\
Phone: n (\%) & $7(13.7)$ \\
Email: n (\%) & $2(3.9)$ \\
Colleague support & \\
$\quad$ Observed session: n (\%) & $2(3.9)$ \\
Phone: n (\%) & $14(27.5)$ \\
Email: n (\%) & $12(23.5)$ \\
\hline
\end{tabular}

$\mathrm{n}=$ number, $\mathrm{v}$-LiFE = Lifestyle-integrated Functional Exercise program for people with vision impairment

\section{Participants}

Older adults with vision impairment

Of the 294 RCT participants randomised to receive v-LiFE, 172 finished the program and were contacted for phone interview between March 2017 and April 2019. Of these, 3 were unreachable or declined interview and 15 had withdrawn from the study. Interviews were ceased at 154 interviews due to thematic saturation, and no more participants invited after this point. Table 3 shows the demographic characteristics of the $154 \mathrm{v}$-LiFE recipients who completed the post-intervention interview.

Table 3. Older adults with vision impairment demographic characteristics $(\mathrm{N}=154)$ 


\begin{tabular}{|c|c|}
\hline Demographic characteristics & $\mathrm{N}=154$ \\
\hline Age in years (range: 52 to 92): mean (SD) & $73.2(10.2)$ \\
\hline Female: n (\%) & $92(59.7)$ \\
\hline \multicolumn{2}{|l|}{ Living status } \\
\hline Live alone: $\mathrm{n}(\%)$ & $66(42.9)$ \\
\hline Spouse only: $\mathrm{n}(\%)$ & $60(39.0)$ \\
\hline Spouse and children: $\mathrm{n}(\%)$ & $15(9.7)$ \\
\hline Relatives/children: n (\%) & $11(7.1)$ \\
\hline Other: n (\%) & $2(0.0)$ \\
\hline \multicolumn{2}{|l|}{ Education } \\
\hline Beyond high school: n (\%) & 79 (51.6) \\
\hline High school: n (\%) & $68(44.4)$ \\
\hline Primary school: n (\%) & $6(3.9)$ \\
\hline Body mass index $\left(\mathrm{Kg} / \mathrm{m}^{2}\right)$ : mean (SD) & $28.4(6.0)$ \\
\hline Comorbidities, n: mean (SD) & $6.6(3.5)$ \\
\hline Legally blind: n (\%) & $134(87.0)$ \\
\hline Visual acuity (LogMAR): mean (SD) & $1.3(1.0)$ \\
\hline Contrast sensitivity: mean (SD) & $0.9(0.7)$ \\
\hline Visual field defect: $\mathrm{n}(\%)$ & $85(55.2)$ \\
\hline \multicolumn{2}{|l|}{ Vision conditions } \\
\hline Age-related macular degeneration: n (\%) & $48(31.2)$ \\
\hline Glaucoma: n (\%) & $31(20.1)$ \\
\hline Retinitis pigmentosa: $\mathrm{n}(\%)$ & $27(17.5)$ \\
\hline Cataract: n (\%) & $22(14.3)$ \\
\hline Stroke / head injury: n (\%) & $17(11.0)$ \\
\hline Diabetic retinopathy: n (\%) & $5(3.3)$ \\
\hline Don't know/other: n (\%) & 75 (48.7) \\
\hline \multicolumn{2}{|l|}{ Number of vision conditions } \\
\hline $1: \mathrm{n}(\%)$ & $103(66.9)$ \\
\hline $2: \mathrm{n}(\%)$ & 35 (22.7) \\
\hline 3: n (\%) & $13(8.4)$ \\
\hline $4: \mathrm{n}(\%)$ & $2(1.3)$ \\
\hline 5: n (\%) & $1(0.6)$ \\
\hline
\end{tabular}

$\mathrm{n}=$ number, $\mathrm{SD}=$ standard deviation

Most recipients were overweight or obese (105/154, $68 \%$; mean body mass index $28.4 \mathrm{~kg} / \mathrm{m}^{2}$, standard deviation (SD) $6.0 \mathrm{~kg} / \mathrm{m}^{2}$ ), were older (mean age 73.2 years, SD 10.2 years), female $(92 / 154,60 \%)$, and with high school or above education $(147 / 154,96 \%)$. The most common vision conditions were age-related macular degeneration $(58 / 154,31 \%)$, glaucoma $(31 / 154,20 \%)$ and retinitis pigmentosa $(27 / 154,18 \%)$. The majority of recipients had only one vision condition $(104 / 154,75 \%)$.

\section{Orientation and Mobility Specialists (Instructors)}

Twenty Instructors were invited to participate in an interview between June and August 2018; of these, eight were unreachable and one declined following initial interest. Interviews were ceased at 11 interviews due to thematic saturation, and no more Instructors invited after this point. Table 4 shows characteristics of the 11 Instructors who completed the interview.

Table 4. Characteristics of the sample of Orientation and Mobility Specialists (Instructors) interviewed ( $\mathrm{n}=11$ )

\begin{tabular}{llrlr}
\hline Instructor & Gender & Years in role & Metropolitan/regional & Older adults with vision impairment trained in v-LiFE, $\mathrm{n}$ \\
\hline 1 & $\mathrm{~F}$ & 17 & Metro & 10 \\
2 & $\mathrm{~F}$ & 4 & Metro & 3 \\
3 & $\mathrm{~F}$ & 2 & Regional & 16 \\
4 & $\mathrm{M}$ & 10 & Metro & 8 \\
5 & $\mathrm{~F}$ & 9 & Metro & 6 \\
6 & $\mathrm{~F}$ & 8 & Metro & 4 \\
7 & $\mathrm{M}$ & 9 & Metro & 2 \\
8 & $\mathrm{~F}$ & 2 & Regional & 6 \\
9 & $\mathrm{~F}$ & 11 & Metro & 8 \\
10 & $\mathrm{~F}$ & 20 & Metro & 1 \\
11 & $\mathrm{~F}$ & & & 1 \\
\hline
\end{tabular}

$\mathrm{F}=$ female, $\mathrm{M}=$ male 
Themes from interviews with recipients and Instructors were mapped broadly onto the behaviour change wheel intervention functions of enablement, education, persuasion, incentivisation, coercion and environmental restructuring. Themes were also mapped to the COM-B model for the individual participant's capability, opportunity and motivation ${ }^{15}$ (summarised in Table 5 with illustrative quotes). Program implementation was also interpreted within habit formation theory ${ }^{20}$ which was the basis for v-LiFE. Overall, recipients were able to access and engage with the program. However, the program was considered too easy for younger recipients or those already undertaking physical activity or exercise. Instructors generally enjoyed delivering the program and saw it as an extension of their work. Although criticism was scarce, there was some criticism of the high number of activities and difficulty in recording activities for a wide range of participants with different levels of vision or ability to utilise technology.

Table 5. Identified themes from semi-structured interviews with older adults with vision impairment and Orientation and Mobility Specialists (Instructors), and behaviour change wheel components

\begin{tabular}{|c|c|c|c|}
\hline \multirow[t]{2}{*}{ Themes } & \multirow[t]{2}{*}{ Quotes } & \multicolumn{2}{|c|}{$\begin{array}{l}\text { Behaviour Change Wheel } \\
\text { Component }\end{array}$} \\
\hline & & $\begin{array}{l}\text { Intervention } \\
\text { functions }\end{array}$ & $\begin{array}{l}\text { Sources of } \\
\text { behaviour } \\
\text { (subset) }\end{array}$ \\
\hline \multicolumn{4}{|c|}{ Older adults with vision impairment perspectives } \\
\hline $\begin{array}{l}\text { Delivery } \\
\text { aptitude }\end{array}$ & $\begin{array}{l}\text { 'Instructors were helpful, making it enjoyable' }(F, 80) \text {, } \\
\text { '...Instructors are very a ware of the vision impairments we have' }(M, 70) \\
\text { 'I found it enjoyable, especially speaking to the ... instructor and how I can improve' }(F, 72) \text {. }\end{array}$ & Enablement & $\begin{array}{l}\text { Opportunity } \\
\text { (Physical) }\end{array}$ \\
\hline \multirow[t]{2}{*}{ Social norms } & \multirow{2}{*}{$\begin{array}{l}\text { 'Yes, [I would recommend it] to anyone with vision problems and balance issues. Particularly those with a cane' (M, } \\
72) . \\
\text { 'I would recommend it to anyone in fact. There's great value in that. Everyone could benefit from increasing their } \\
\text { balance and strength, and those with vision impairment' (F, 66). } \\
\text { 'I think it would be better suited to more elderly people and less active people' (F, 59) } \\
\text { 'Not really but this is mostly likely because I am young and still active. These exercises seem more suitable for older } \\
\text { adults and those who are not as active or have really bad vision or other disabilities' (F, 61) }\end{array}$} & $\begin{array}{l}\text { Education, } \\
\text { persuasion, } \\
\text { incentivisation } \\
\text { \& coercion }\end{array}$ & $\begin{array}{l}\text { Motivation } \\
\text { (Reflective) }\end{array}$ \\
\hline & & $\begin{array}{l}\text { Education, } \\
\text { training \& } \\
\text { enablement }\end{array}$ & $\begin{array}{l}\text { Capability } \\
\text { (Psychological) }\end{array}$ \\
\hline \multirow[t]{2}{*}{$\begin{array}{l}\text { Habit } \\
\text { formation }\end{array}$} & \multirow{2}{*}{$\begin{array}{l}\text { '(I) have modified the way I (do) daily activities: hanging clothes on line with a sideways steps, tandem walk while } \\
\text { waiting for toast' }(\mathrm{M}, 68) \text {. } \\
\text { 'I didn't like the daily activity ones and didn't have time for them so instead [the Instructor] and I set them up to do } \\
\text { them all in sets together' }(\mathrm{M}, 68) \text {. }\end{array}$} & \multirow{2}{*}{$\begin{array}{l}\text { Environmental } \\
\text { restructuring } \\
\text { \& enablement }\end{array}$} & $\begin{array}{l}\text { Opportunity } \\
\text { (Physical) }\end{array}$ \\
\hline & & & $\begin{array}{l}\text { Motivation } \\
\text { (Automatic) }\end{array}$ \\
\hline \multicolumn{4}{|c|}{ Instructor perspectives } \\
\hline $\begin{array}{l}\text { Individualised } \\
\text { adaptations }\end{array}$ & $\begin{array}{l}\text { 'I guess it's like what we do in O\&M... it's second nature... I modify everything for every person. Because the } \\
\text { technique is still the same but the instructions have to change or the environment has to change' (F, } 17 \text { years, } 10 \\
\text { older adults with vision impairment). } \\
\text { 'I'd go through that first assessment to see what they could do and then if I felt that they could do a little less of that } \\
\text { level, but with some kind of considerable modification I would try that with them, but I'd let them tend to guide me' } \\
\text { (F, } 2 \text { years, } 16 \text { older adults with vision impairment). }\end{array}$ & $\begin{array}{l}\text { Environmental } \\
\text { restructuring } \\
\text { \& enablement }\end{array}$ & $\begin{array}{l}\text { Opportunity } \\
\text { (Physical) }\end{array}$ \\
\hline $\begin{array}{l}\text { Complimentary } \\
\text { to scope of } \\
\text { practice }\end{array}$ & $\begin{array}{l}\text { 'I just enjoyed the program as a whole; teaching them [older adults with vision impairment] the activities that } \\
\text { helped improve their strength and balance and just seeing how much of an improvement it makes to them over the } \\
\text { course of time.' (F, } 8 \text { years, } 5 \text { older adults with vision impairment). } \\
\text { 'I thought the booklets and how it was all done there for you; you didn't really have to think about it, you just did it. } \\
\text { You just followed the step-by-step and followed the structure and you can change and you can modify as you go' (F, } \\
17 \text { years, } 10 \text { older adults with vision impairment). }\end{array}$ & Incentivisation & $\begin{array}{l}\text { Motivation } \\
\text { (Automatic) }\end{array}$ \\
\hline $\begin{array}{l}\text { Challenges to } \\
\text { delivery }\end{array}$ & $\begin{array}{l}\text { 'I found it difficult embedding the number of activities into some of everyday routines, especially with older clients. } \\
\text { It can be difficult for them to remember even a few activities. Yes, there are ways to document or record the } \\
\text { activities or the routines that it was embedded into, but again, because there's so many it just can be difficult to } \\
\text { keep track for clients' (F, } 4 \text { years, } 3 \text { older adults with vision impairment) } \\
\text { 'I've had a couple that were not computer savvy either or didn't have any text to speech so it's just been } \\
\text { [challenging] how they record it and how they remember to do the activities' (F, } 8 \text { years, } 4 \text { older adults with vision } \\
\text { impairment) }\end{array}$ & $\begin{array}{l}\text { Enablement \& } \\
\text { environmental } \\
\text { restructuring }\end{array}$ & $\begin{array}{l}\text { Opportunity } \\
\text { (Physical) }\end{array}$ \\
\hline
\end{tabular}

O\&M = Orientation and Mobility, v-LiFE = Lifestyle-integrated Functional Exercise program for people with vision impairment

\section{Older adults with vision impairment perspectives}

Delivery aptitude. Although not explicitly asked, delivery by Instructors was well-regarded based on a perceived good understanding of how vision influences mobility, and the need to adapt activities accordingly. Recipients also appreciated the regular one-on-one sessions in their home and found the program pace well-suited to them.

Social norms. Recipients reported that they would recommend the program to someone like themselves, including those with or without vision impairment, particularly because the program is individualised and aims to improve strength and balance. Recipients who said they would not recommend the program to someone like themselves were usually younger ( $\leq 65$ years) and stated the program would be more appropriate for someone older or less mobile.

Habit formation. Either embedding v-LiFE activities into daily routines or doing the activities in sets was reported. For most, embedding was the preferred method. This aligns with habit formation theory, whereby behaviours are repeated in response to contextual cues, until which point they become 
automatic. ${ }^{20}$ However, some recipients preferred to modify the program so that activities were done together rather than throughout the day, often because of time constraints, or preference for a more traditional set-based exercise program.

Orientation and Mobility Specialist (Instructor) perspectives

Individualised adaptations.

Number of sessions. Views were divided among Instructors about whether they should modify program length for each participant or not. For those who didn't, it was usually because of concern about deviating from the research protocol. All Instructors reported that if the program was rolled out as part of usual service delivery in the future, they would vary session number based on recipients' circumstances.

Program materials. Typically, recipients' level of vision had the most impact on whether materials were used and/or modified. For those with functional vision, the activity planner and activity counter were used to record activity completion. For those with low vison, the planner and counter were modified with less text/increased font size. For those with low or no vision, tactile markers were used to aid or replace the activity planner or counter. Other technologies, such as voice recorders or electronic documents were used for some. For those who lived with others, a family member often assisted with completing the activity planner and counter.

Complimentary to scope of practice. All Instructors interviewed reported feeling comfortable and supportive delivering the v-LiFE program to older adults with vision impairment. The benefits experienced by recipients during the program were particularly motivating, and the clear structure of the program was appreciated by the Instructors. Conversely, Instructors reported that other work priorities, such as travel and data collection for the RCT, were external barriers to delivering the program.

Challenges to delivery. Although reported challenges were scarce, Instructors noted two main challenges when delivering the v-LiFE program to older adults with vision impairment. The first related to the large number of activities recipients were required to embed into their daily routine, particularly those who were older or with cognitive issues. The second related to recording activities; although there were many options to record activities, there were instances where Instructors had difficulty finding a method appropriate to the recipient's vision, memory or technological ability.

\section{Discussion}

This study revealed that Instructors made dynamic adaptations to the v-LiFE program, individualised to the circumstances and motivations of each recipient. The study findings suggest that this program can successfully be delivered to older adults with vision impairment, with Instructors requiring minimal ongoing training and support. Delivery of an individualised exercise-based fall prevention program by Orientation and Mobility Specialists may be a viable mode of delivery for older adults with vision impairment.

Environmental restructuring and enablement were found to be particularly instrumental to the positive attitudes of recipients and Instructors in the delivery of the v-LiFE program. Environmental restructuring and enablement facilitate behaviour change through changing the physical or social context, and increasing means and reducing barriers, respectively. ${ }^{15}$ People are often reluctant to participate in falls prevention programs due to competing priorities, as well as

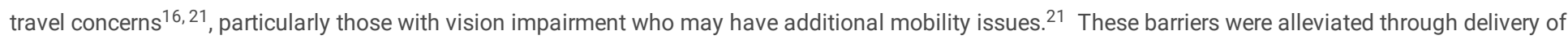
the v-LiFE program in the home, and tailoring the mode of activity completion (activities completed throughout the day or in a block). Also, the program was delivered by professionals with expertise delivering individualised programs to people with vision impairment, further improving recipients' physical opportunity (a source of behaviour) to participate in the program.

A motivational barrier to participation for some of the younger ( $\leq 65$ years) or more active recipients was that they did not perceive a need to reduce their risk of falling. Elskamp et $\mathrm{al}^{21}$ investigated reasons people refuse to participate in falls prevention trials, and similarly found that younger and more active participants considered themselves 'too healthy' to participate in a falls prevention program, despite having presented at an Emergency Department due to a fall. However, participants did recognise the benefits for other older adults. ${ }^{21}$ These findings are consistent with other similar studies ${ }^{16}$, as well as those targeted at older adults with vision impairment ${ }^{22}$, which concluded that people do not want to consider themselves at risk of falls because of the negative connotations associated with this perception. A point of difference in this study is that our participants agreed to and participated in a fall prevention trial, and still considered the program not suitable for them. According to the COM-B model, reflective motivation can be improved through education, persuasion, incentivisation and coercion. ${ }^{15}$ It is possible our participants did not realise or did not want to think they were at risk of falls; did not recognise the additional functional benefits related to improvements in strength and balance from participating in an exercise fall prevention program; or weren't overly challenged by program activities. Adaptations to this particular program are needed to make it more motivating to younger, more active people with vision impairment. In a small feasibility study, Schwenk et $\mathrm{al}^{23}$ have adapted LiFE for younger people (60-70 years; aLiFE) with the inclusion of enhanced balance and strength activities and activities targeting agility and sedentariness. It may be that the activities need to include more challenging opportunities and be tailored to specific deficits.

Environmental restructuring and enablement were particularly relevant for Instructors. The results of this study indicate that Instructors consider the v-LiFE program complimentary to their existing scope of practice. The additional adaptations reported by Instructors also indicate that their perspectives are key to continued development and refinement of the program for people with vision impairment.

To date, there is no proven exercise-based falls prevention program for people with vision impairment ${ }^{7}$, despite demonstrated benefits to falls prevention in other high-risk populations. Evidence-based interventions are frequently adapted for different populations, but these adaptations are not always well

Page $7 / 10$ 
documented. ${ }^{24}$ It is critical to document these adaptations in order to understand the impacts specific adaptations may have on the positive findings when these programs are evaluated for effectiveness. ${ }^{25}$ The practical adaptations reported in this paper can inform future research and further integration of public health interventions for people with vision impairment.

\section{Strengths and limitations}

Strengths of this study are the in-depth investigation of the perspectives of both receivers and deliverers of a novel program, and a rigorous analysis process using an accepted theoretical framework. Further, Instructors were trained in and delivered a state-wide program across regional and metropolitan areas. However, a limitation is that the questions asked of recipients may not have been adequate in eliciting responses based on the adaptation of the program for people with vision impairment. For example, the researcher who conducted these interviews noted that recipients found it challenging to answer the question regarding 'unexpected outcomes'. Further, this study was being delivered by personnel of a highly-respected organisation, so recipients may not have felt confident being critical about program delivery. Last, the Instructors who accepted the invitation to interview were more likely interested in falls prevention or positive about the program, and perspectives of those who did not enjoy delivering the program may not have been accounted for.

\section{Conclusion}

Delivery of falls prevention programs by Orientation and Mobility Specialists may fill the gap in program delivery for people with vision impairment, as this study demonstrated successful delivery with training and modest ongoing support. Effectiveness of the program in this population as a means to prevent falls is forthcoming, following completion of the randomised trial. ${ }^{11}$ The current study has the potential to inform developers of exercise programs for the prevention of falls in older adults with vision impairment, or those looking to include people with vision impairment into existing programs. This study provides practical suggestions for delivery, through documenting initial and ongoing adaptations, and gives a true sense of how this program works within dynamic, real-world service delivery. Perspectives of instructors and older adults with vision impairment are critical to the ongoing development of pragmatic and accessible falls prevention programs which can be delivered at scale.

\section{List Of Abbreviations}

$\begin{array}{ll}\text { LiFE } & \text { Lifestyle-integrated Functional Exercise } \\ \text { v-LiFE } & \text { LiFE adapted for older adults with vision impairment } \\ \text { F } & \text { Female } \\ \text { Instructor } & \text { Male } \\ \text { NSW } & \text { Orientation and Mobility Specialist } \\ \text { ACT } & \text { Australian Capital Territory } \\ \text { RCT } & \text { Randomised Controlled Trial } \\ \text { AFRIS } & \text { Attitudes to Falls-Related Intervention Scale } \\ \text { SD } & \text { Standard Deviation } \\ \mathrm{n} & \text { Number }\end{array}$

\section{Declarations}

Ethics approval and consent to participate: Ethics approval for the larger RCT and post-intervention interviews with participants was granted by the University of Sydney Human Research Ethics Committee (2016/787); all participants were informed of the objectives, methods, and procedures of data collection. Their rights to confidentiality, anonymity, and voluntary withdrawal from study participation were explained and assured. Written informed consent to participate was obtained from all participants. Ethics approval for the semi-structured interviews with Instructors by the University of New South Wales Human Research Ethics Committee (HC180362). Their rights to confidentiality, anonymity, and voluntary withdrawal from study participation were explained and assured. Verbal informed consent to participate was obtained from all participants.

Consent for publication: Not applicable

Availability of data and materials: The datasets used and/or analysed during the current study are available from the corresponding author on reasonable request.

Competing interests: The authors declare that they have no competing interests

Funding: This work was funded by the Australian National Health and Medical Research Council (NHMRC project grant APP1108176) and is supported by Guide Dogs NSW/ACT. Lisa Dillon is supported by an Australian Government Research Training Program Scholarship. The funding body had no role in the

Page $8 / 10$ 
design of this study, in collection, analysis and interpretation of data, and in writing the manuscript.

Authors' contributions: LD was responsible for the conception, design, data collection, data analysis, and was the major contributor in writing the manuscript. LK contributed to conception, design and data analysis. HN contributed to qualitative data collection and interpretation of findings. FT and JM contributed to conception and design. LC contributed to design and interpretation of findings. All authors read and approved the final manuscript.

Acknowledgements: We acknowledge Jo Munro as the physiotherapist who trained and provided Instructors with ongoing support throughout this study.

\section{References}

1. Australian Bureau of Statistics. Population Projections Australia 2012 to 2101. http://www.ausstats.abs.gov.au/ausstats/subscriber.nsf/0/13D196FB0DBECC3BCA257C2E00173FAD/\$File/32220_2012\%20(base)\%20to\%202101.pdf (2013). Accessed 20 Feb 2019.

2. Kannus P, Khan KM, Lord SR. Preventing falls among elderly people in the hospital environment. Med J Aust. 2006;184:372-373.

3. Piirtola M, Era P. Force platform measurements as predictors of falls among older people - a review. Gerontology. 2006;52:1-16.

4. Ivers RQ, Cumming RG, Mitchell P, Attebo K. Visual impairment and falls in older adults: the Blue Mountains Eye Study. J Am Geriatr Soc. 1998;46:58-64.

5. Legood R, Scuffham P, Cryer C. Are we blind to injuries in the visually impaired? A review of the literature. Inj Prev 2002;8:155-160.

6. Sherrington C, Michaleff ZA, Fairhall N, Close JC, Lord SR. Exercise to prevent falls in older adults: an updated systematic review and meta-analysis. Br J Sports Med. 2017;51:1750-1758.

7. Dillon L, Clemson L, Ramulu P, Sherrington C, Keay L. A systematic review and meta-analysis of exercise-based falls prevention strategies in adults aged 50+ years with visual impairment. Ophthalmic Physiol Opt. 2018;38:456-467.

8. Clemson L, Fiatarone Singh MA, Bundy A, Cumming RG, Manollaras K, O'Loughlin P, Black D. Integration of balance and strength training into daily life activity to reduce rate of falls in older people (the LiFE study): randomised parallel trial. BMJ. 2012;345:e4547. doi: 10.1136/bmj.e4547

9. Clemson L, Munro J. Conceptual model of habit reforming to improve balance and prevent falls. In: Pachana NA, editor. Encyclopaedia of Geropsychology. 1st ed. Singapore: Springer; 2016. p. 1-10.

10. Keay L, Saich F, Clemson L, Middlemiss L, Johnson J, Tumanik H, Taylor J, Munro J, Borkowski E, Tinsley F. Feasibility and acceptability of orientation and mobility instructors delivering the LiFE falls prevention program to older people with vision impairment. International Journal of Orientation and Mobility. 2015;7:22-33.

11. Keay L, Dillon L, Clemson L, Tiedemann A, Sherrington C, McCluskey P, Ramulu P, Jan S, Rogers K, Martin J, Tinsley F, Jakobsen KB, Ivers RQ. PrevenTing Falls in a high-risk, vision-impaired population through specialist ORientation and Mobility services: protocol for the PlaTFORM randomised trial. Inj Prev 2018;24:459-466.

12. Virgili G, Rubin G. Orientation and mobility training for adults with low vision. Cochrane Database Syst Rev 2006;3:CD003925. doi: 10.1002/14651858.CD003925.pub2

13. Academy for Certification of Vision Rehabilitation \& Education Professionals (ACVREP). Certified Orientation and Mobility Specialist (COMS) handbook, section 2 - scope of practice for orientation and mobility certification. https://www.acvrep.org/certifications/coms-scope. Accessed 20 Feb 2019.

14. Bennett S, Bennett JW. The process of evidence-based practice in occupational therapy: Informing clinical decisions. Aust Occup Ther J. 2000;47:171180.

15. Michie S, van Stralen MM, West R. The behaviour change wheel: a new method for characterising and designing behaviour change interventions. Implement Sci. 2011;6:42. doi: 10.1186/1748-5908-6-42

16. Yardley L, Donovan-Hall M, Francis, Todd C. Attitudes and beliefs that predict older people's intention to undertake strength and balance training. J Gerontol B Psychol Sci Soc Sci. 2007;62:119-125.

17. Campbell AJ, Robertson MC, La Grow SJ, Kerse NM, Sanderson GF, Jacobs RJ, Sharp DM, Hale LA. Randomised controlled trial of prevention of falls in people aged $>$ or $=75$ with severe visual impairment: the VIP trial. BMJ. 2005;331:817. doi: 10.1136/bmj.38601.447731.55

18. Gale NK, Heath G, Cameron E, Rashid S, Redwood S. Using the framework method for the analysis of qualitative data in multi-disciplinary health research. BMC Med Res Methodol. 2013;16:117. doi: 10.1186/1471-2288-13-117

19. Boutron I, Moher D, Altman DG, Schulz KF, Ravaud P. Extending the CONSORT statement to randomized trials of nonpharmacologic treatment: explanation and elaboration. Ann Intern Med. 2008;148:295-309.

20. Gardner B, Lally P, Wardle J. Making health habitual: the psychology of 'habit-formation' and general practice. Br J Gen Pract. 2012;62:664-666.

21. Elskamp AB, Hartholt KA, Patka P, van Beeck EF, van der Cammen TJ. Why older people refuse to participate in falls prevention trials: a qualitative study. Exp Gerontol 2012;47:342-345

22. Dillon L, Duffy P, Tiedemann A, Keay L. Acceptability of fall prevention strategies for older people with vision impairment. International Journal of Orientation \& Mobility 2018;9:1-9.

23. Schwenk M, Bergquist R, Boulton, Van Ancum JM, Nerz C, Weber M, Barz C, Jonkman NH, Taraldsen K, Helbostad JL, Vereijken B, Pijnappels M, Maier AB, Zhang W, Becker C, Todd C, Clemson L, Hawley-Hague H. The adapted Lifestyle-Integrated Functional Exercise program for preventing functional decline in young seniors: development and initial evaluation. Gerontology. 2019;65:362-374

24. Stirman SW, Miller CJ, Toder K \& Calloway A. Development of a framework and coding system for modifications and adaptations of evidence-based interventions. Implement Sci. 2013;8:65. doi: 10.1186/1748-5908-8-65

Page $9 / 10$ 
25. Aarons GA, Sklar M, Mustanski B, Benbow N \& Brown CH. "Scaling-out" evidence-based interventions to new populations or new health care delivery systems. Implement Sci. 2017;12:111. doi: 10.1186/s13012-017-0640-6

\section{Additional Files}

Additional file 1 - Attitudes to Falls-Related Intervention Scale (AFIRS) Semi-structured Interview Questions for participants Additional file 2 - Semi-structured Interview guide with Orientation and Mobility Specialists (Instructors)

\section{Figures}

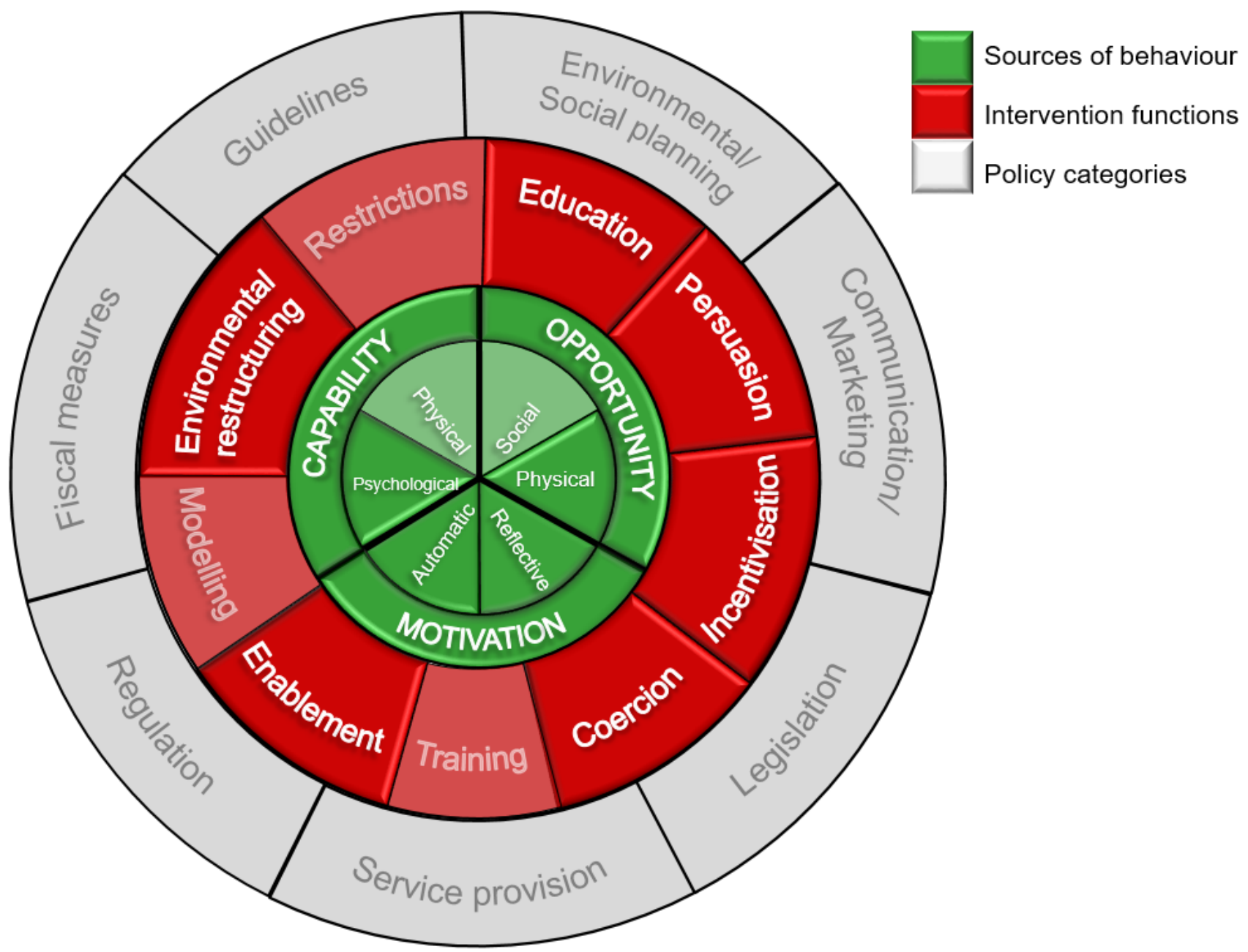

Figure 1

Behaviour Change Wheel (adapted from Michie et al15) with highlighted components identified in the present study.

\section{Supplementary Files}

This is a list of supplementary files associated with this preprint. Click to download.

- supplement1.pdf

- supplement2.pdf

- supplement3.pdf 